Review

\title{
Energy Scenario Analysis for the Nordic Transport Sector: A Critical Review
}

\author{
Raffaele Salvucci ${ }^{1, *}$, Stefan Petrović ${ }^{1}{ }^{1}$, Kenneth Karlsson ${ }^{1}$, Markus Wråke ${ }^{2}$, \\ Tanu Priya Uteng ${ }^{3}$ and Olexandr Balyk ${ }^{1}$ D \\ 1 DTU Management, Technical University of Denmark, Produktionstorvet, Building 424, 2800 Kgs. Lyngby, \\ Denmark; stpet@dtu.dk (S.P.); keka@dtu.dk (K.K.); obal@dtu.dk (O.B.) \\ 2 Energiforsk AB, Swedish Energy Research Centre, Olof Palmes gata 31, 10153 Stockholm, Sweden; \\ markus.wrake@energiforsk.se \\ 3 Institute of Transport Economics, Norwegian Centre for Transport Research (TØI), Gaustadalléen 21, \\ 0349 Oslo, Norway; Tanu.PriyaUteng@toi.no \\ * Correspondence: rafs@dtu.dk; Tel.: +45-52634679
}

Received: 5 April 2019; Accepted: 6 June 2019; Published: 12 June 2019

check for Abstract: Experiencing the highest growth in emissions since 1990 and relying mainly on oil, transport
is considered the most complicated sector to decarbonize. Lately, the Nordic countries have shown
remarkable success in reducing greenhouse gas (GHG) emissions, especially in the power and heat
sector. However, when it comes to transportation, the greatest source of Nordic GHG emissions,
stronger measures are needed. Relying on a rich and diversified portfolio of renewable sources and
expertise, the Nordic countries could benefit from a common mitigation strategy by encompassing a
larger variety of solutions and potential synergies. This article reviews studies addressing integrated
energy and transport scenario analysis for the Nordic region as a whole. The studies targeted are
those applying energy system models, given their extensive adoption in supporting scenario analysis.
Most notable of these studies is the "Nordic Energy Technology Perspectives 2016 " to which a special
focus is dedicated. The article reviews the methodological choices and the research content of the
selected literature. Challenges/limitations are identified in light of recent transport research, and
categorized as: "transport behavior", "breakthrough technologies", "domestic energy resources"
and "geographical aggregation and system boundaries". Lastly, a list of suggestions to tackle the
identified gaps is provided based on the existing literature.

Keywords: alternative fuels; decarbonization; energy system modelling; low-carbon transition; NETP 2016; sustainable mobility; transport behavior

\section{Introduction}

The transport sector is responsible for $23 \%$ of global greenhouse gas (GHG) emissions (2015 data), and it has the least diversified energy demand among all sectors, relying almost entirely on oil products [1]. In its baseline scenario outlined in the Energy Technology Perspectives (ETP), the International Energy Agency (IEA) estimates a 75\% increase of global energy consumption in transportation by 2050 and a consequent doubling of associated $\mathrm{CO}_{2}$ emissions [2]. Countries worldwide have already declared long-term mitigation measures in their National Determined Contributions. However, their commitments are still not in line with the Paris Agreement [3], which calls for more ambitious actions. In order to facilitate a transition to a low-carbon transportation sector, IEA suggests the adoption of a combination of three technological and behavioral measures: avoiding travel demand, modal shift and improvements in vehicle efficiency [4].

In the Nordic region, the transport sector represents the greatest source of GHGs. It accounts for almost $40 \%$ of total $\mathrm{CO}_{2}$ emissions, which is higher than the global average. However, the Nordic 
countries are pioneers in deploying sustainable energy technologies, each with its peculiarities: e.g. wind power in Denmark, hydropower in Norway, biomass in Finland and Sweden and geothermal energy in Iceland. Moreover, the well-integrated Nordic regional electricity market is enabling a high penetration of renewables, for instance connecting Norwegian hydro reservoirs to Danish wind farms in periods with a lack of demand. Besides the power and heat sector, the Nordic transport sector has also started a slow sustainable transition. For instance, the aggressive policy support for electric cars (especially in Norway) has recently made the Nordic region the third largest electric car market by volume of sales in the world, just after China and the United States [5]. However, the Nordic transport sector is still far from decarbonization.

Relying on a rich portfolio of diversified renewable energy sources and expertise, Nordic countries could benefit by outlining a common Nordic mitigation strategy by encompassing a larger variety of sustainable solutions and possible synergies [6]. Moreover, the Nordic region is already today in a favorable position in creating first-mover advantages regarding the low-carbon technological transition [7]. Therefore, besides benefitting from reducing their own emissions, the Nordics could eventually help other European countries in achieving their environmental goals by exporting the developed solutions and expertise.

Energy system models have been supporting long-term decision making for the energy sector for long time and for different countries [8], representing valuable and powerful tools for identifying specific technology deployment pathways under alternative policy scenarios. Energy system analysis has been extensively applied also to investigate dedicated decarbonization strategies for specific sectors such as heat [9], residential [10] and transport [11,12]. However, despite the potential benefits in outlining a common Nordic strategy, most of the available literature focuses on single countries, e.g. Denmark [11,13], Iceland [14], Norway [15] and Sweden [12], while the Nordic region as a whole is addressed only by few studies, calling for further analyses.

The aim of this article is to review the state of the art of studies applying energy system analysis for integrated energy and transport scenarios for the Nordic region, and to provide recommendations for future research. Specifically, the studies targeted are those addressing the Nordic region as a whole, enabling the identification of possible synergies across countries, thus studies focusing on single Nordic countries are not reviewed. The identified literature is analyzed in terms of methodological choices adopted and research content targeted. Among all the studies reviewed, a special focus is given to the "Nordic Energy Technology Perspectives 2016" (NETP 2016) [16], which, despite being published three years ago, still represents the most complete study assessing future energy scenarios for the Nordic region. Based on the critical review of the selected literature, research gaps are identified and discussed in light of recent findings in transport research. In particular, the gaps are organized in four main categories: 1) transport behavior, 2) breakthrough technologies, 3) domestic energy resources and 4) geographical aggregation and system boundaries. A list of solutions to tackle the identified gaps is provided based on additional literature including also single Nordic country analyses.

In Section 2, the criteria adopted for the review are provided. In Section 3, the results of the review are presented. Section 4 identifies the research gaps and discusses the motivation to fill them. Moreover, a set of best practice examples is provided based on additional relevant literature, and insights on the implications of adopting such practices are discussed within an energy system modelling rationale. Finally, Section 5 articulates the conclusions.

\section{Review Methodology}

The Nordic countries are in a favorable position in deploying a common long-term strategy for a sustainable future transport sector. Indeed, the synergic exploitation of national energy sources, technology expertise and infrastructure could facilitate such low-carbon transition. In light of the above, the focus of this review is on studies addressing long-term energy scenario analysis for a low-carbon Nordic transport sector, applying energy system modelling. In particular, energy system analysis represents a well-established scientific discipline that has been extensively used for decades to 
support future scenario analyses. Moreover, the geographical scope of the review is the Nordic region as a whole; therefore, studies focusing on a single Nordic country are omitted. However, some of them are discussed together with additional relevant literature in Section 4 . The aim of the article is to provide an up-to-date overview of existing literature on the topic, identify limitations and research gaps and propose suggestions for future studies targeting the same research area.

The review was carried out during March 2019 through three main steps. First, an automatic literature search of journal articles was performed through online academic databases, namely, Web of Science [17], DTU Findit [18] and Scopus [19]. Then a manual screening was executed to filter out irrelevant studies. Lastly, the assembled literature was integrated with additional relevant reports and book chapters selected manually based on the authors' knowledge.

Concerning the automatic database screening, the string adopted for the search was formulated as follows: (transport* OR "transport system" OR "transport sector") AND (scenario*) AND (energy system* OR "energy system analysis") AND (Nordic* OR Scandinavia* OR "Northern Europe"). The search was performed for the topic field in Web of Science, All fields in DTU Findit and Title, abstract and key words in Scopus. The search led to a total of 95 hits, which has been progressively reduced to 8 after including only works in English, removing duplicates and excluding irrelevant research areas and journals. In addition, studies with a focus on only a single Nordic country were omitted. The manual screening was carried out first by title and then by reading the abstract and, eventually, if necessary, the full article.

In Section 3.1, the identified studies are commented based on their specific research questions and the methodology applied. A special focus is given to the NETP 2016 [16], which stands as the most complete study assessing future energy scenarios for the Nordic region. The NETP 2016 results are analyzed with a particular focus on the transport sector analysis, and in terms of methodological tools and modelling choices (Section 3.2). The NETP 2016 review is based on publicly available reports and data (accessible at [20]), as well as on more detailed model results provided by IEA and Nordic Energy Research (NER), and on personal communications with scientists involved.

\section{Results}

Section 3.1 presents the results of the literature review, while Section 3.2 describes in details the NETP 2016 methodological approach and results.

\subsection{Nordic Transport Energy Scenarios}

There are several studies investigating long-term energy scenarios for a low-carbon Nordic transport sector, which address specific research questions from different perspectives. In this study, the focus is on works applying energy system analysis as methodological tool, and addressing the Nordic region as a whole. Usually, the research questions targeted, in the identified articles, involve the investigation of the potential role of a specific transport technology in the decarbonization of the Nordic transport sector. The adoption of specific technologies is analyzed in terms of effect on the overall energy system or part of it. Broadly speaking, the most common technologies investigated are electric vehicles (EVs), and the adoption of first- and second-generation biofuels and hydrogen as alternative transport fuels.

The effect of a high penetration of EVs in the Nordic energy system is the most investigated topic, which is usually addressed via optimization and linear programming. In particular, the effect of different charging scenarios on the day-ahead energy planning and on the yearly electricity demand and transmission requirements up to 2050 are analyzed in [21] and [22], respectively. Other studies focus on the role of EVs for a future low-carbon road transportation in the Northern European area (Scandinavia and Germany). Reference [23] applies the Balmorel energy system model up to 2030 to investigate the effect EVs on the power system, while [24] studies the impact of EVs on the electricity generation capacity and dispatch, including the use of electrified roads for trucks and buses. Additional information on Balmorel can be found in [25]. 
Concerning biofuels, the deployment of forest-based (second generation) biofuels as a long-term mitigation strategy to decarbonize the Fenno-Scandinavian (Norway, Finland and Sweden) road transport sector is addressed in [26] applying an input-output model. The analysis investigates the production of biofuels and their consumption in the transport sector under different assumptions including future technology deployments and demand projections up to 2050. However, most of the studies dealing with energy scenarios for biofuels are country specific, e.g. [27] and [12]. Since the scope of this review is the Nordic region, national studies are omitted.

The role of hydrogen in the transition towards a $100 \%$ renewable Northern European energy system is investigated by [28]. In particular, Balmorel is applied to study the effect of hydrogen penetration in the power, heat and transport sector up to 2060. A similar study [29] estimates, via simulation, the effect of hydrogen and biofuels penetration in the transport sector on the Northern European power sector for the year 2060. Reference [30] analyzes the technical and economic potential of different hydrogen technologies (production and consumption) in the Nordic region. Namely, a linear-programing, technology-based hydrogen energy model is applied under different assumptions regarding fossil fuel prices, technology costs and hydrogen demands to investigate the role of hydrogen in the Nordics until 2030.

Lastly, besides the energy system modelling approach, some studies analyze the long-term decarbonization of the Nordic transport sector from other perspectives. For instance, ref. [31] analyzes three technology platform value chains for a sustainable Nordic road transport, namely e-mobility, hydrogen fuel cell vehicles and advanced liquid and gaseous biofuels. However, such works are out of the scope of this review.

Only few of the identified studies address the research question of how to achieve a low-carbon transport sector taking into account the entire Nordic energy system. These studies go beyond the sole interaction between, e.g. the power and transport sectors, but they explicitly account for all the other sectors (from the supply to, e.g. industry and households). Such studies provide a more comprehensive analysis of how to achieve a low-carbon Nordic energy system while providing sector specific insights including dedicated transport analysis. For instance, [32] applies a TIMES (The Integrated MARKAL-EFOM System) model of the Scandinavian energy system to investigate pathways towards carbon neutrality by 2050. The transport sector is analyzed under a "no import of biofuels" assumption and a low electrification of heavy duty vehicles, resulting in hydrogen as the dominant fuel. Furthermore, [33] analyzes how to achieve a 100\% renewable share of primary energy supply in the Nordics by 2050 applying TIMES-VTT, a full energy system model of Denmark, Finland, Norway and Sweden. The study investigates the role of power-to-gas technologies under different assumptions involving the availability of forest biomass for energy use and the penetration of biofuels and hydrogen in the transport sector. More information on TIMES models are provided by [34].

To summarize, all the mentioned studies analyze long-term low-carbon energy scenarios for the Nordic transport sector. They address specific research questions, which are usually centered around a single or limited set of technologies. The integration of the studied technologies is usually investigated with respect to only a part of the energy system, for instance, the power sector. Only a few studies include the whole energy system [32,33]. The inclusion of the whole energy system in the analysis allows the identification of synergies between technologies and of resource competition across sectors while fulfilling common environmental targets. Lastly, most of the identified studies focus only on road transportation, while either neglecting the rest of the transport sector or including it partially.

To the authors' best knowledge, despite the fact a few years have elapsed since its original publication, the most comprehensive study addressing long-term energy scenarios for a low-carbon Nordic transport sector is the NETP 2016 [16], the second of this series. In this series of studies, the modelling framework includes the whole Nordic energy system. This enables the investigation of cross-sectorial and cross-country solutions and resource allocation, while providing insights on the possible role of specific transport technologies in the decarbonization of the Nordic transport sector (including rail, navigation and aviation). The NETP 2016 strives for ambitious goals while adopting a 
quantitative approach. It relies on a solid modelling framework from the ETP studies, which results in a well-documented and integrated analysis. NETP studies represent a benchmark within the energy arena, as witnessed by the numerous articles referring to the NETP 2016 results. Few examples are given by [35], which comments upon the NETP 2016 results from a social and political point of view, while [32] refers to the NETP 2016 findings for comparisons. For this reason, Section 3.2 thoroughly reviews the NETP 2016, focusing on the findings for the sole transport sector. Moreover, the NETP 2013 study is not reviewed, since the findings of NETP 2016 are directly built upon it.

Lastly, the Nordic region is also addressed by studies targeting integrated energy and transport scenario analysis for larger geographical areas, such as the European [36] or even the global one [37]. However, given the relative size of Nordic countries on the European and global scale, these studies usually pose little focus on the Nordic region compared to dedicated Nordic studies; hence, they are not part of this review.

\subsection{NETP 2016}

NETP 2016 follows the principles of the ETP series of studies by IEA [16], whose aim is to identify sustainable energy technology transition pathways, globally and for specific regions. The ETP-TIMES model represents the backbone of the approach. It is a cost driven bottom-up optimization model including the five Nordic countries (Denmark, Finland, Iceland, Norway and Sweden) as separate model regions. ETP-TIMES represents the Nordic energy conversion sectors (electricity generation, refineries, etc.) and is soft-linked to three end-use sector models (namely industry, buildings and transport), utilized to derive projections of final energy demands. ETP-TIMES identifies the least-cost technology mix to meet the final energy demands for the whole time horizon under several constraints mirroring the different scenario assumptions ([16], p. 221). These constraints range from feasible renewable energy potentials and $\mathrm{CO}_{2}$ prices to policy instruments [38]. Two additional tools support ETP-TIMES. A linear dispatch model analyzes the operation of the electricity sector and assesses the need for flexible generation and storage in the energy system obtained from the ETP-TIMES model. Besides, the Balmorel model investigates the electricity trades and transmission expansions within the Nordic region and towards Europe ([16], p. 222).

Among the end-use sector models, the transport sector is represented by the Mobility Model (MoMo) developed by IEA [39]. MoMo is a techno-economic spreadsheet and simulation model capable of making detailed projections of transport and vehicle activity, energy demand, direct and well-to-wheel (WTW) GHG and pollutant emissions ([16], p. 224). Population and gross domestic product (GDP) projections together with private vehicle ownership rates are key drivers to calculate the service demand, or alternatively, the vehicle demand, depending on the mode [40]. Modal shares and average efficiency improvements for different technologies are exogenously estimated by experts [41]. Energy consumption and emissions are calculated based on the ASIF identity [42].

The whole NETP 2016 analytical framework refers to an urban and a non-urban dimension. Due to the lack of a common definition of urban areas, the respective national definitions were adopted for each country. The urban/non-urban disaggregation in NETP 2016 is achieved as in ETP 2016. This process involves a number of assumptions and regression analysis to fill the data gaps ([1], p. 144) (Appendix A.1).

NETP 2016 focuses on a central scenario, the Carbon Neutral Scenario (CNS), where Nordic energy related $\mathrm{CO}_{2}$ emissions drop by $85 \%$ by 2050 compared to 2013 levels. The less ambitious Nordic 4 Degree Scenario (4DS) is also included. It reflects the Nordic contribution to the IEA's global 4DS ([16], p. 35), where the global increase in GHG emissions is limited to $20 \%$ relative to 2013 levels ([1], p. 32). The CNS and 4DS are the results of a mix of scenario types, back-casting and forecasting ([16], p. 219). This scenario approach is applied in different ways. ETP-TIMES uses an optimization algorithm, while MoMo outlines a solution through simulation, which is guided by manual iterated adjustments to mirror what experts believe to happen given a specific set of assumptions. The procedure consists of supplying the projected transport demands, given a set of technological options and a specific carbon 
budget. The priority is given to energy efficiency improvements and to the deployment of cheaper sustainable solutions (given the different technology cost curves). Finally, the penetration of expensive technologies are allowed if part of the demand is still uncovered [43]. For instance, in aviation, due to the future demand growth, efficiency maximization and fuel shift towards biofuels were insufficient to keep the emissions below the carbon budget. Therefore, a shift towards high-speed rail (expensive technology) was necessary to be included in the CNS [43]. For more information regarding the NETP 2016 scenario building process, refer to Appendix A.2.

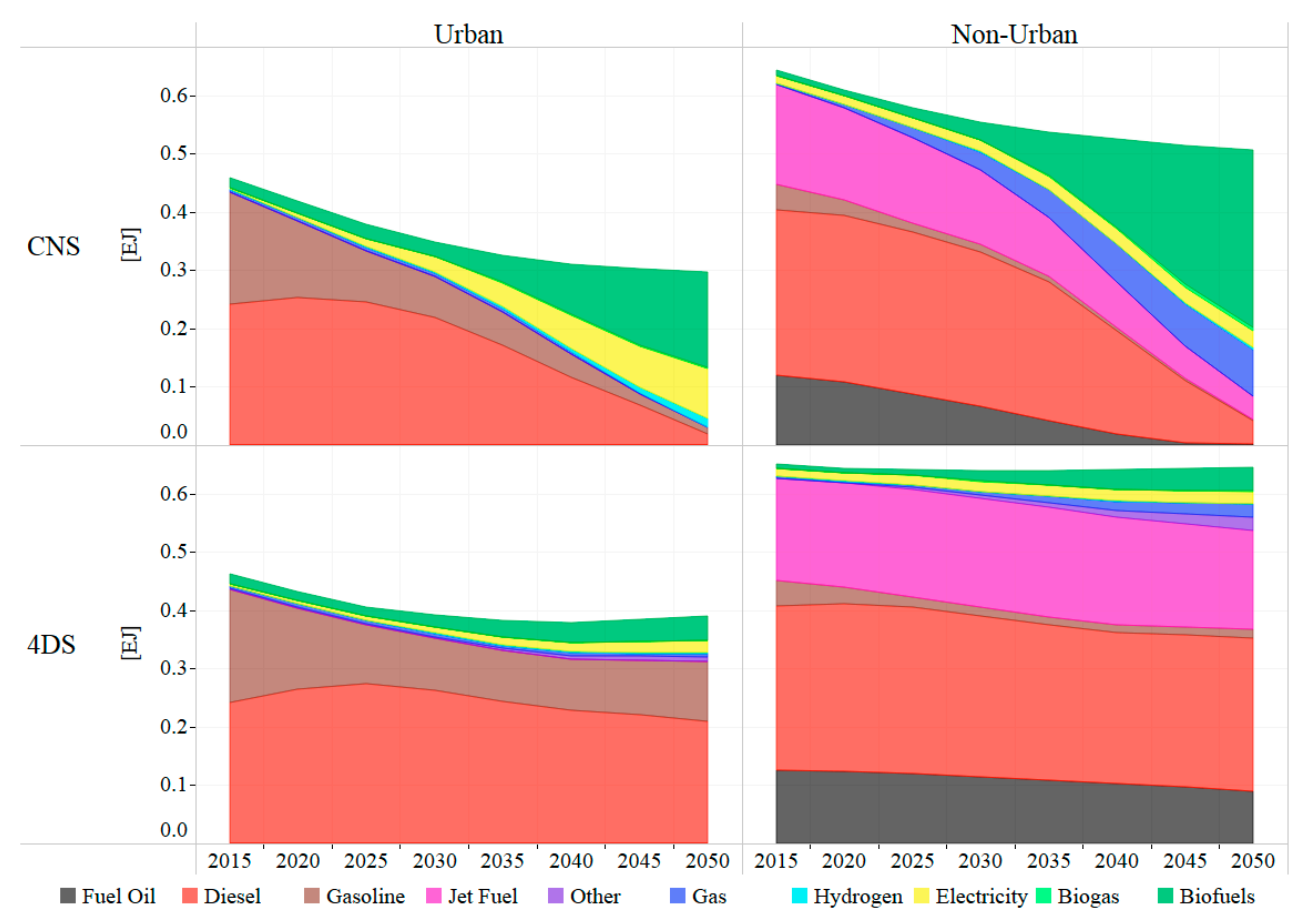

Figure 1. Nordic transport final energy demand (EJ) in urban and non-urban areas. Including international aviation and shipping, excluding pipeline transport. Results from MoMo, provided by [44], are interpolated with a five-year step resolution. "Biofuels" includes ethanol, biodiesel, bio oil, and bio jet fuel, while "Other" includes gas- and coal-to-liquid fuels.

Concerning the NETP 2016 results, from 2015 to 2030, the CNS and 4DS have similar final energy demands (Figure 1). In the following period, the CNS is more ambitious, requiring considerable improvements in vehicles fuel economy ([16], p. 66), and a higher penetration of renewable fuels. In the CNS, by 2050, transport final energy demand drops by $20 \%$ compared to 2000 levels, reaching 0.87 EJ despite a $70 \%$ increase in total transport activity. This happens due to energy savings (especially among cars), but also to modal shift towards more efficient modes and slightly to non-motorized modes in urban areas ([16], p. 123). For instance, high-speed rail covers $13 \%$ of the growing aviation transport demand ([16], p. 70). In 2050, fossil fuels account only for $25 \%$ of final energy use, biofuels represent the highest consumption category with $60 \%$ (around $0.48 \mathrm{EJ}$ ), while electricity represents slightly more than $10 \%$. Biofuel vehicles cover mainly long distance, heavy duty road and marine freight and aviation transport demands. On the other hand, electric vehicles cover light and mid duty freight and short distance passenger trips, especially in urban areas. Powertrains have higher efficiencies than internal combustion engines (ICEs), resulting in lower energy consumption. Indeed, electric vehicles, including battery electric (BE), plug-in hybrids and hybrids, represent $78 \%$ of the stock in 2050, followed by fossil fuel ICE vehicles (21\%) and fuel cell (FC) electric vehicles (1.4\%). In particular, hybrids dominate among trucks operating in non-urban areas with $62 \%$ of the stock, followed by diesel ICE vehicles (22\%). Lowering emissions in the transport sector would require a tight cooperation among Nordic countries. The broad electrification of urban transport in the CNS 
is based on a synergistic coordination to integrate and decarbonize the Nordic electricity market. The high penetration of wind power relies on more active use of Norwegian and Swedish hydropower through a highly interconnected power system. The deployment of high-speed rail would require the development of an infrastructure network linking Nordic capitals. Lastly, the large import of biofuels calls for a joint Nordic collaboration to research and develop advanced biofuels and a strategy to efficiently utilize the Nordic biomass across regions and sectors.

Within the 4DS, in 2050 transport final energy demand stabilizes at 1.10 EJ (Figure 1), thanks to efficiency improvements in passenger light duty vehicles (LDVs) and a moderate deployment of hybrids, though, $88 \%$ of final energy demand in 2050 is still supplied by fossil fuels, followed by biofuels $(8 \%)$ and electricity $(4 \%)$. Fossil ICE vehicles represent $60 \%$ of the stock followed by hybrids $(27 \%)$, while the rest is shared among BE and FC electric vehicles.

In the CNS, WTW GHG emissions face a 70-80\% reduction compared to 2015 levels (Figure 2). Tank-to-wheel (TTW) GHG emissions drop by $40 \%$ within the same period. This is also possible thanks to the almost fully decarbonized Nordic electricity system in 2050. In the 4DS, transport activities in 2050 account for 10\% lower WTW GHG emissions than 2015 levels ([16], pp. 71).

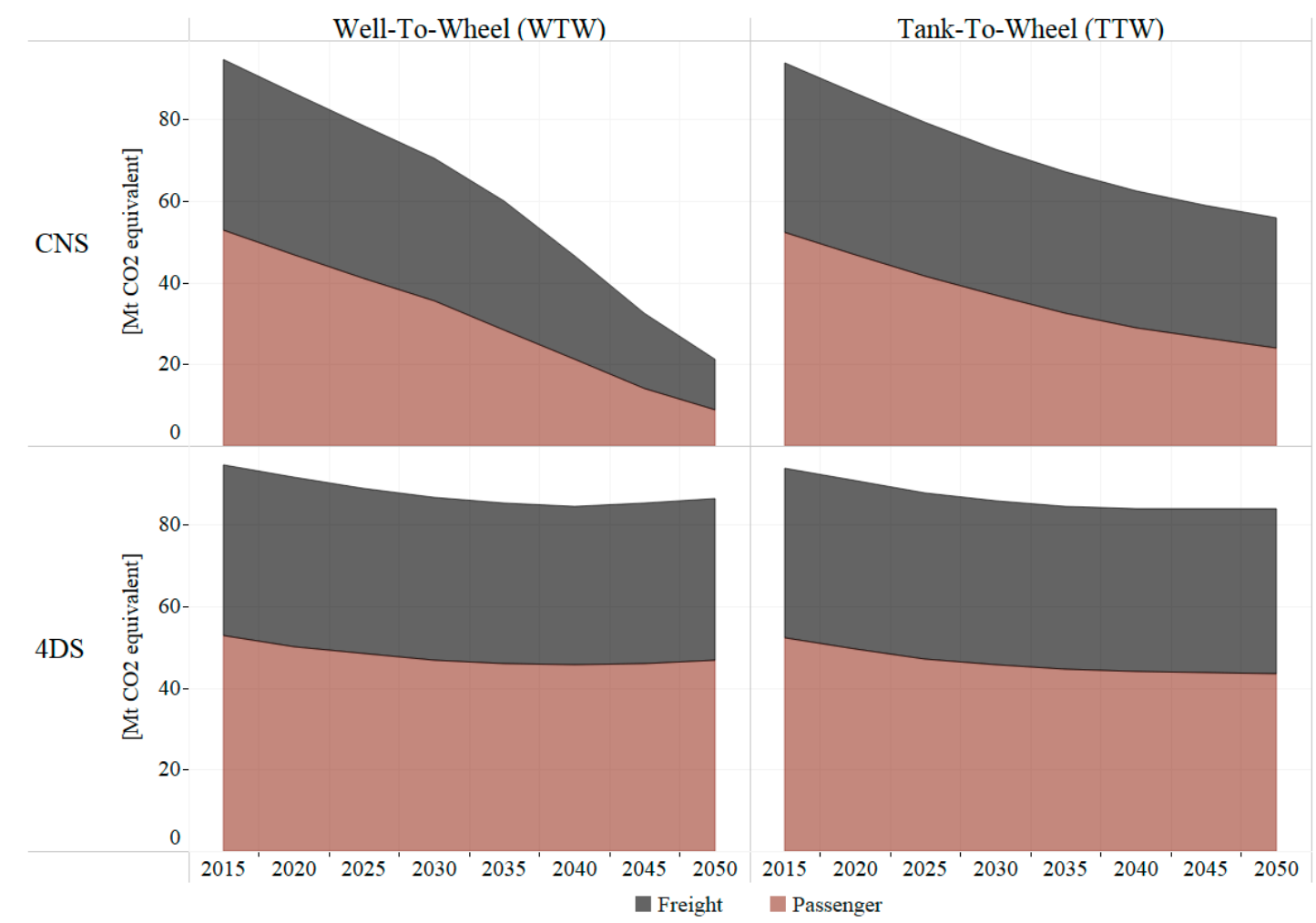

Figure 2. Well-to-wheel (WTW) and tank-to-wheel (TTW) GHG emissions in the CNS and 4DS. Results from MoMo, provided by [44], are interpolated with a five-year step resolution.

\section{Discussion-Identified Challenges and Recommendations}

In light of the literature review, some recommendations are drawn for future long-term energy scenario analysis for a low-carbon Nordic transport sector. In particular, challenges and gaps are identified in the reviewed literature based on recent findings in transport research tackling sustainable mobility. The identified gaps are categorized as: "Transport behavior", "Breakthrough technologies", "Domestic energy resources" and "Geographical aggregation and system boundaries". Recommendations to overcome the identified gaps are based on forefront studies targeting long-term energy scenario analysis for the transport sector but including other geographical scopes than the reviewed one. Table 1 summarizes the studies identified by the authors, which tackle the identified gaps 
in their methodological framework. Each of the examples is commented in terms of effects/repercussions on the scenario analysis within an energy system modelling rationale.

Table 1. Examples of studies tackling the identified challenges in their works.

\begin{tabular}{lc}
\hline \multicolumn{1}{c}{ Challenges } & Solution Examples \\
\hline Transport behavior & {$[11,45-49]$} \\
Modal competition & - \\
Autonomous vehicles and MaaS & \\
\hline Breakthrough technologies & {$[50]$} \\
Electrified roads & {$[51-54]$} \\
Fuel cell and battery electric trucks & - \\
Electric ferries & {$[55-58]$} \\
Carbon capture and storage & {$[12]$} \\
\hline Domestic energy resources & {$[59]$} \\
Biofuels-2nd generation & \\
Electrofuels & {$[47]$} \\
\hline Geographical aggregation and system boundaries & \\
\hline Urban dimension & \\
\hline
\end{tabular}

The following sub-sections discuss separately the identified gaps by introducing motivation, discussion and recommendations.

\subsection{Transport Behavior}

As pointed by [60], the behavioral dimension is crucial when investigating mitigation solutions for transport energy-related $\mathrm{CO}_{2}$ emissions. However, energy-economy-environmental-engineering (E4) models are still weak at simulating behavioral changes. There have been some attempts to fill this gap by incorporating behavioral features in integrated energy and transport models [61]. However, these attempts do not appear in most of the reviewed Nordic studies. The NETP 2016 represents an exception; behavioral aspects are included in MoMo. In particular, vehicle ownership rates are mapped with respect to income and GDP per capita applying Gompertz type curves, while mileage is mapped with respect to income and fuel prices. In ambitious scenarios, where policies promoting modal shift are put in practice in a specific country, the reduction in car ownership is obtained by moving to a lower Gompertz curve based on what observed in other countries in the past. However, emerging phenomena deeply dependent on the behavioral dimension, such as autonomous vehicles, car-sharing, car-pooling and in general mobility as a service (MaaS) are only indirectly considered when estimating car ownership reduction and efficiency increase potentials (due to more efficient driving patterns) ([16], p. 120). The direct inclusion of the behavioral dimension in E4 models could enable the investigation of behavioral change policies. This is particularly relevant when new mobility trends are integrated in the analysis as it gives the possibility to assess effective policies promoting the adoptions of such measures. Moreover, non-motorized modes are not directly modelled in MoMo, though they are considered when estimating passenger transport activity in urban areas. The explicit modelling of such modes could allow analyses of interactions between them and public transport or, potentially, MaaS in terms of complementarity or synergies as underlined by [62].

As presented in [61], the inclusion of behavior into integrated energy and transport models recognize two main approaches. The first involves linking the E4 model with an external transport model incorporating the behavioral dimension. The second approach consists of broadening the E4 classical framework to integrate some transport specific variables/dimensions to emulate transport behavior in order to estimate endogenously, for example, modal choice or shift. NETP 2016 can be roughly categorized in the first group. The remaining studies reviewed include E4 models with an aggregated/partial representation of the transport sector, where behavior is not endogenously modelled. 
Concerning the second approach, there are several methods to include behavior in E4 models. For instance, $[11,45,46]$ emulate modal shift by integrating the concept of travel time budget and transport infrastructure, $[47,48]$ introduce endogenous modal choice through modelling modal level of service and consumers' decisions, while [49] adopts substitution elasticities to enable modal shift. These approaches include different levels of transport behavior in E4 models and thus offer different capabilities, and require different data sources. Therefore, such methodological adoption is dependent on the specific research question addressed by practitioners. However, enhancing the capability of E4 models to capture behavior dynamics when investigating policies, represents a desirable improvement when tackling transport energy scenarios. For instance, the mentioned methodologies are capable of enabling endogenous modal shift, one of the pivotal measures identified by the IEA and the European Commission $[4,63,64]$ for a low-carbon passenger and freight transport sector. In addition, emerging phenomena largely affected by behavior such MaaS (including car-sharing and car-pooling) and autonomous vehicles could be investigated in a more direct way. Indeed, autonomous vehicles could reduce congestion and car ownership and increase mileage (more efficient use of the fleet), especially if coming along with car sharing and pooling, and provide electricity storage in the case of electric vehicles [65]. Nevertheless, if wrong policies are in place, they could instead increase congestion and transport activity. However, no studies including explicitly these emerging mobility phenomena in energy system models were found by the authors.

\subsection{Breakthrough Technologies}

Lately, innovation in transport technologies has gained strong momentum. Therefore, the inclusion of up-to-date breakthrough technologies in the modelling framework is challenged by the continuous innovation pace. However, some emerging technologies particularly interesting for the Nordic case can be identified.

In the NETP 2016, electrified roads and fuel cell trucks are identified to have the potential of suppling part of the long distance road freight transportation ([16], p. 21). Despite this, electrified roads are excluded from the analysis, while fuel cell trucks are only partially included due to their technical and economic uncertainty. The authors recognize the benefit in outlining a scenario demonstrating that policy targets can be achieved with well-known and available technologies. However, the NETP 2016 could have employed less probable and innovation rich scenarios (also known as "wild cards" or "black swans") to test the response of the system under circumstances "beyond the expectations", as recognized by [35]. The inclusion of electrified roads in the analysis represents a desirable improvement, especially considering that electric and hybrid vehicles are highly deployed within the NETP 2016 scenarios, for both LDVs and trucks (Section 3.2). In addition, pilot projects assessing their technical and economic feasibility are ongoing in Sweden, Germany and USA [66], which can provide preliminary figures. Moreover, a high deployment of hydrogen long haul trucks and battery powered regional trucks could be interesting, especially when considering limited bioenergy resources [32].

Electric ferries represent another interesting technology that can support a low-carbon transport sector in the Nordics. In MoMo, shipping includes only freight transportation while maritime passenger transport is not directly included. The reason behind such modelling architecture is that the biggest shipping energy demand worldwide resides in the freight sector. However, maritime passenger transportation causes roughly a quarter of total shipping emissions taking place in the Nordic waters, namely 6.5 Mtonnes of annual $\mathrm{CO}_{2}$ emissions [67]. In particular, electric ferries are under development by different companies in the Nordics [68]. Moreover, "green" coastal shipping is compliant with one of the main barrier to expand coastal shipping, which is coastal air quality, therefore, it represents also an attractive alternative for the growing freight road transportation.

Summarizing, electrified roads, FC and BE trucks and electric ferries represent potential breakthrough technologies for the Nordic region. The inclusion of these technologies in the scenario analysis would enable the assessment of the impacts of hydrogen and electricity demands on the whole energy system. This is particularly important in the Nordics, where the electricity system is already 
accommodating large amounts of intermittent sources (e.g. wind power), and thus hydrogen production and electricity smart charging could represent additional flexibility sources [28]. Considering the available literature, some studies analyze the effect of electrified roads on the power system through the representation of their electricity demand as done by [24]. To the authors' knowledge, the only study including explicitly such technology in an E4 model is represented by [50]. This study evaluates the economic viability of electrified roads in the decarbonization of the Danish transport sector. An explicit inclusion of hydrogen long haul trucks and battery powered trucks appear in more studies, addressing, for instance, energy scenarios for South Africa [51], Japan [53,54] and even globally [52]. Lastly, no studies including electric ferries in energy system models are available.

Another interesting emerging technology is carbon capture and storage (CCS). In the Nordics, the adoption of CCS is particularly interesting for emissions reduction in the heavy industries [69]. This is reflected in the NETP 2016 CNS, where a wide adoption of CCS accounts cumulatively for almost 30\% of total direct industrial $\mathrm{CO}_{2}$ emissions reduction over the period 2020-2050 [16] (p. 24). Even though CCS cannot be directly applied in the transport sector, its inclusion in the analysis is interesting when looking at dedicated scenarios for the sole transport sector. In particular, when the full energy system is described in the modelling platform, and a common environmental goal is set up (such as a carbon budget), CCS technologies can provide flexibility in reducing emissions across the sectors. For instance, CCS can free biomass feedstocks for biofuels production in sectors where alternative solutions are limited (such as aviation or heavy industries [27]). Moreover, the development of bio-energy with carbon capture storage (BECCS) technologies has recently grown in interest in the Nordic countries [70], given their tradition in heat and power generation from biomass and the large potential for feedstocks. BECCS technologies could be employed to obtain negative emission "credits" from the combustion of biomass to be spent in other sectors.

The inclusion of CCS technologies as a mitigation option in E4 models is nowadays nearly a common practice, e.g., [55-58]. Including an up-to-date CCS technology portfolio in the analysis of low-carbon energy scenarios for the transportation sector, could provide additional cross-sectorial solutions for transport modes whose emissions are harder to reduce (e.g. aviation). This is particularly relevant in a region with large $\mathrm{CO}_{2}$ storage potential, such as the Nordic one [71].

\subsection{Domestic Energy Resources}

The use of bioenergy as a mitigation measure represents a controversial topic. In the CNS, the Nordic region becomes a net importer of bioenergy, by increasing net biofuel imports four times to meet the growing demand in transport, which in 2050 represents two thirds of total final energy use (0.48 EJ, Figure 1). This vision is contextualized within a carbon constrained global context where, most likely, the demand for bioenergy will increase as well. Decarbonizing the Nordic transport sector relying heavily on biofuels imports could be questionable in terms of sustainability; therefore, [32] includes a scenario where bioenergy imports to the Scandinavian region are excluded. The authors recommend following a similar approach when investigating sustainable pathways for the Nordic region, to challenge the studied scenarios with net zero bioenergy imports and to investigate an efficient strategy to allocate domestic biomass feedstocks across the sectors. Furthermore, there are several promising emerging biofuel conversion pathways (mostly forest-based or second-generation) [72], whose inclusion in energy system models is growing in interest, as shown by [73]. Concerning the independence from alternative fuels imports, electrofuels represent also a promising option for transportation to include in the scenarios [74]. Besides providing an alternative to fossil fuels, also in those cases where solutions are limited (such as aviation) [75], electrofuels offer energy storage capability for intermittent renewables, as wind and photovoltaics.

Given the high potential for domestic biofuel production in the Nordics [76], an up-to-date bio-refinery technology portfolio is recommended to be included in the analysis, as done, for example, by [12] in the MARKAL_Sweden model. The same applies for electrofuels, whose role in decarbonizing the Nordic transport sector could be investigated quantitatively by including them in the modelling 
framework, as done by [59] in the JRC-EU-TIMES model. Lastly, hydrogen, besides being used in the electrofuel production, represents a potential alternative transport fuel itself, whose production technologies should also be included, as often done, in E4 models, such as by [77]. Implementing an exhaustive representation of alternative fuel production chains in energy system models provides two main benefits. First, it sheds lights on the optimal use of domestic energy resources. Secondly, in the case of hydrogen and electrofuels, it provides insights on energy storage capabilities in a system with high penetration of variable renewables, such as the Nordic.

\subsection{Geographical Aggregation and System Boundaries}

Due to the increasing urbanization and its potential for deploying specific sustainable mobility solutions, the urban area is often mentioned as an increasingly important dimension when analyzing the future of mobility [16] (see Appendix A.1). In particular, Nordic capitals are already global leaders in sustainable transportation (Copenhagen's bike lanes, Oslo's electromobility, Stockholm's public transport) ([16], p. 108) and thus represent cutting-edge case studies. Moreover, urban planning influences considerably transport behavior, not just driving patterns but also modal choice [78]. Therefore, urban planning represents itself a long-term policy instrument for energy demand reduction, which should be integrated in the scenario discussion [79]. However, the urban dimension is neglected in the modelling framework for most of the reviewed studies. The NETP 2016 represents an exception, where, for the first time within the ETPs, the urban dimension is analyzed with special focus and dedicated tools.

The authors encourage practitioners to capture the urban dimension in their integrated energy and transport analyses to depict the great potentials of cities in deploying effective mitigation measures, particularly for the Nordic case. This is especially true for long-term scenario analysis, where the slow changes in the urban structure, which usually involve a long time span, become feasible and open for policy discussion. Several energy system models have been developed for specific cities to support integrated energy and transport analysis such as for Malmø [80], Oslo [81] and the Helsinki region ([16], p. 232). Other studies differentiate between urban and non-urban transportation in national E4 models. One example is given by [47], which provides a modelling design characterizing transportation across the urban, suburban and rural areas for Denmark.

In addition, when investigating energy pathways for a low-carbon transportation sector in the Nordic countries, addressing these countries as parts of a unique system can shed lights on additional solutions by encompassing more options and synergies. However, it is crucial to keep a detailed description of the individual countries, given their differences in, e.g. the geography, resources availability and travel habits, which result in heterogeneous transport challenges [82]. This is done for example by [32,33]. Instead, in the NETP 2016, Nordic countries in MoMo are aggregated into two regions: "EU Nordic" (Denmark, Finland and Sweden) and "Non EU Nordic" (Iceland and Norway). The split of results at a country level is achieved with approximate methods mainly based on population [43]. The lack of a Nordic country subdivision in MoMo, is due to its application in the wider focus of the ETP studies. Thus, efforts enhancing the level of details have been directed towards those regions where emissions and energy demands are dominant in a global context. The authors suggest depicting single country description in the modelling framework even when addressing the Nordic region as a whole. This enables to identify synergies across countries when pursuing a common goal while suggesting country specific strategies and policies in light of national resources and major differences in the energy and transport systems.

A similar suggestion can be drafted for the energy system depicted by the modelling platform. Indeed, including all sectors of the energy system in the analysis, as done by $[16,32,33]$, can shed lights on resource competition and technological synergies across sectors when fulfilling common environmental targets, such as the exploitation of waste heat from bio refineries as heating source.

In addition, in ETP-TIMES, each Nordic country is modelled as a single region since the ETP 2013 study. In the NETP 2016, the electricity trade across the different power regions is assessed with the 
support of the Balmorel model. An interesting improvement could be to model the power regions inside the main modelling framework, as done by [32], allowing interregional trade of electricity and, potentially, of other commodities (e.g. domestic biomass or hydrogen), resulting in a fully integrated tool. This is especially relevant considering all the above suggestions, involving the inclusion of different energy carriers and their production chains. Moreover, with the exception of the NETP 2016, in most of the reviewed studies, international shipping and aviation are not part of the analysis. However, effective strategies for reducing emissions in such sub-sectors will also be needed; therefore, their inclusion in the analysis is necessary for a more exhaustive outlook.

Lastly, in the CNS, WTW emissions were claimed to drop by 70-80\% in 2050 compared to 2015 levels (Figure 2). In particular, well-to-tank (WTT) emissions contribute largely to the overall reduction (Section 3.2). The GHG balance of fuel pathways production assumed for the WTT emissions calculations are retrieved from the Joint Research Centre (JRC) life-cycle assessment (LCA) study [83,84]. Such study adopts a system expansion approach to account for co-products obtained in the fuel production pathways (incremental approach). Emissions avoided due to co-products substitution are considered in the GHG balance as emission credits. The identification of such co-products depends strongly on the system boundaries and methodological assumptions defined within the LCA goal and scope, which, in this case, has a European focus. This assumption implies that transport fuel production chains are assumed located in a generic European context. This has specific repercussions on the emissions calculations. For example, in the case of electricity substitution, emissions savings are higher in a European context compared to the Nordic one, due to a higher carbon content. Even though the CNS relies heavily on biofuels imports, their future provenience is uncertain. A remarkable portion of the claimed reduction in the transport GHG emissions is based on figures valid within the goal and scope of the LCA study, which are different from the NETP 2016, undermining the solidity of the obtained results. Moreover, the avoided emissions for fuel production pathways are not accounted for other sectors. A more solid and consistent approach for GHG emissions accounting across the whole analytical framework is desired. The authors encourage the accounting of WTT emissions as long as they are consistently integrated in the analysis framework. For instance, they could be directly calculated by including fuel production chains in the modelling platform as suggested above.

Moreover, the inclusion of non- $\mathrm{CO}_{2}$ emissions in the modelling framework is a good practice. In fact, the use of alternative fuels in the transport sector could bring some surprises if other GHGs besides $\mathrm{CO}_{2}$ are left unchecked. For instance, incomplete methane combustion in ICEs or leakages from pipelines could represent a possible issue, given its larger global warming potential compared to carbon dioxide [85].

Lastly, except for the urban dimension, the authors do not provide examples to tackle the rest of the suggestions since they represent only modelling choices and do not involve any novelty.

\section{Conclusions}

This article reviews the state of the art of studies applying energy system analysis for integrated energy and transport scenarios for the Nordic region. The identified studies are reviewed in terms of methodological choices and research content. A special focus is posed on the NETP 2016, which stands as one of the most complete analysis of future energy scenarios for the Nordic region. Based on the systematic and critical review, challenges and solutions are identified for the following categories: 1) transport behavior, 2) breakthrough technologies, 3) domestic energy resources and 4) geographical aggregation and system boundaries.

The inclusion of transport behavior into the modelling framework, enabling, for example, endogenous modal shift, is a desirable improvement. In addition, capturing transport behavioral change could allow detailed analysis of emerging mobility trends such as autonomous vehicles and MaaS, whose direct inclusion is also identified as a potential improvement.

The inclusion of breakthrough technologies, such as electrified roads, FC and BE trucks, and electric ferries in energy system models is particularly interesting for the Nordic case. These technologies 
could rely on an almost decarbonized power sector and potentially provide demand side flexibility to a system with a large amount of intermittent renewables. Besides, the inclusion of CCS technologies could provide additional (cross-sectorial) solutions for those transport modes whose emissions are harder to reduce (e.g. aviation). However, the inclusion of CCS in energy system models is almost a common practice.

A sustainable use of biomass represents another important challenge, particularly relevant in a future carbon constrained world. Therefore, the authors recommend the inclusion of up-to-date second-generation biofuel conversion and electrofuel production technologies to investigate domestic alternatives to large biofuels import.

Due to the growing urbanization and the great potential that cities have in deploying green mobility solutions, we recommend depicting the urban dimension in the modelling platform. At the same time, we suggest to keep a distinctive representation of single countries to capture national resources and peculiarities, such as travel habits and geographic features. In addition, an explicit representation of the power regions (bidding areas) is particularly relevant considering the potential role of electricity in the future Nordic transportation, while including the full energy system could provide insights on cross-sectorial solutions. Besides, the full transport sector, including international shipping and aviation, should be addressed when analyzing the Nordic emission reduction strategies. Lastly, modelling other GHGs besides $\mathrm{CO}_{2}$ is recommended, together with consistently integrated WTT calculations.

For each of the identified challenges, we have provided recommendations to tackle them based on the existing literature. However, in some specific cases, such as electric ferries, MaaS (including car-sharing and car-pooling) and autonomous vehicles, no previous studies were found. These challenges represent opportunities for further research. Finally, some of the improvements suggested (such those relative to alternative energy carriers and CCS) are also valid outside the narrow paradigm of integrated energy and transport analysis.

Author Contributions: R.S. performed the review and wrote the manuscript. S.P., K.K., M.W., T.P.U. and O.B. revised the manuscript and provided important recommendations. In particular, K.K., M.W. and O.B. helped with analyzing the modelling framework adopted in the NETP 2016 project. T.P.U. provided support on commenting upon the NETP 2016 transport scenarios analyses. All authors read and approved the final manuscript.

Funding: This research was part of the Nordic Flagship Project SHIFT funded by Nordic Energy Research (grant number 77892).

Acknowledgments: The authors wish to thank Pierpaolo Cazzola and Jacob Teter (International Energy Agency) for their insightful comments and precious advices regarding the MoMo model and its application within the NETP 2016 study. The work presented in this paper is a result of the research activities of the SHIFT (Sustainable Horizons for Transport) project (grant number 77892), funded by The Nordic Energy Research.

Conflicts of Interest: The authors declare no conflict of interest. The funders had no role in the design of the study; in the collection, analyses, or interpretation of data; in the writing of the manuscript, or in the decision to publish the results.

$\begin{array}{ll}\text { Abbreviations } \\ 4 \mathrm{DS} & \text { 4 Degree Scenario } \\ \mathrm{BE} & \text { Battery Electric } \\ \mathrm{BECCS} & \text { Bio-Energy with Carbon Capture Storage } \\ \mathrm{CCS} & \text { Carbon Capture Storage } \\ \mathrm{CNS} & \text { Carbon Neutral Scenario } \\ \mathrm{CO}_{2} & \text { Carbon Dioxide } \\ \mathrm{E} 4 & \text { Energy-Economy-Environmental-Engineering } \\ \mathrm{ETP} & \text { Energy Technology Perspectives } \\ \mathrm{EVs} & \text { Electrical Vehicles } \\ \text { FC } & \text { Fuel Cell } \\ \text { GDP } & \text { Gross Domestic Product } \\ \text { GHG } & \text { Greenhouse Gas }\end{array}$




$\begin{array}{ll}\text { GIS } & \text { Geographical Information System } \\ \text { IEA } & \text { International Energy Agency } \\ \text { ICE } & \text { Internal Combustion Engine } \\ \text { JRC } & \text { Joint Research Centre } \\ \text { LCA } & \text { Life-Cycle Assessment } \\ \text { LDVs } & \text { Light Duty Vehicles } \\ \text { MaaS } & \text { Mobility as a Service } \\ \text { MoMo } & \text { Mobility Model } \\ \text { NER } & \text { Nordic Energy Research } \\ \text { NETP } & \text { Nordic Energy Technology Perspectives } \\ \text { TIMES } & \text { The Integrated MARKAL-EFOM System } \\ \text { TTW } & \text { Tank-To-Wheels } \\ \text { WTT } & \text { Well-To-Tank } \\ \text { WTW } & \text { Well-To-Wheels }\end{array}$

\section{Appendix A}

The Appendix A provide additional insights on the methodological framework applied within the NETP 2016 study. In particular, Appendix A.1 deepens into the reasoning of the urban and non-urban dimension characterization and how is achieved quantitatively. Appendix A.2 provides additional insights on the scenarios conceptualization and on how foresight theory is applied.

\section{Appendix A.1 Urban Dimension towards Sustainable Development}

For the first time within the ETPs, ETP 2016 and NETP 2016 analyze the urban dimension with a special focus and dedicated tools. When looking at sustainable development, the urban dimension is identified as central for different reasons. Within the Nordic region, $85 \%$ (2013) of the population lives in cities, and the urbanization rate is expected to triplicate within the next 35 years [16] (p. 42). Therefore, the urban areas will increasingly play a major role in terms of energy demand, in particular with respect to transport and buildings. In addition, cities have a unique potential for deploying specific sustainable technologies, which are benefiting from high population density (economy of scale) and relatively short distances, such as district heating and EVs. Lastly, Nordic capitals are already innovation hubs and global leaders in supporting high quality public transport and non-motorized modes, besides setting more ambitious strategies than their national governments, as Copenhagen's 2025 carbon neutrality ([16], pp. 108, 117).

Concerning the transport sector characterization, geographical information system (GIS) analyses are used to identify high-density urban areas suitable of high capacity public transport (e.g. railways). Passenger two and three wheelers are assumed exclusively urban, passenger air transport is entirely allocated to non-urban areas together with heavy freight trucks, rail and sea transport ([1], p. 219). Vehicle stocks allocation is based on the United Nations database provided by [86]. Mileages characterization are based on average travel time and speed in urban areas, and fuel economies are assumed $10 \%$ worse in urban areas than the original values ([16], pp. 61, 112). Lastly, two additional models, TIMES-HelsinkiMetro and TIMES-Oslo, are used to analyze two "real city cases", the Helsinki region and the city of Oslo respectively. However, such studies are not linked to the main analytical framework $[87,88]$. Thus, due to their freestanding nature, such analyses are not included in this review.

\section{Appendix A.2 Scenario Types in the NETP 2016}

NETP 2016 involves a mix of scenario types from a reference year (2013) to 2050. Based on the nomenclature of Börjeson et al. [89] for foresight theory conceptualization, those scenarios represent a predictive approach (forecast and what if types) able to identify the most likely development to happen given specific conditions, and a normative approach addressing the question: "How can a specific target be reached?" [89]. The first scenario type usually provides an insight on how far the 
development will go compared to the desirable future if no actions would be taken or under specific choices (bifurcation point), the second aims at identifying changes needed to reach the end goal vision.

Different types of argumentations are articulated within the NETP 2016 in order to justify a specific picture of the future, in both approaches (predictive and normative). For the predictive case, such argumentations serve to justify the solidity of the selected future, convincing the audience that all the other possibilities are less likely to happen given certain conditions. For the normative case, argumentations are used to filter in or out possibilities considered incoherent or infeasible with the aimed target (desirable future), as for example, a deployment of a specific technology. These argumentations usually have their roots in the observation of the present situation (historical data).

An example of how the normative approach is applied within the NETP 2016 is represented by the case of FC electric vehicles, which, in the CNS and 4DS, do not cover a main role compared to other technologies, for different reasons. Firstly, hydrogen production is limited by the competition with other forms of electricity storage, such as pumped hydro, and by the limited availability of low cost excess electricity in the portrayed future, where the development of a better integrated market for electricity is considered pivotal across scenarios. The second argumentation is related to the investment in infrastructures (as e.g. centralized production and adequate local distribution) that is, nowadays, considered risky for the hydrogen case ([16], p. 69). Thus, FC electric vehicles are almost excluded from being a possible solution to Nordic mobility, through argumentations regarding their possible deployment in the chosen future. Such argumentations, based on present scientific knowledge, serve to assess the feasibility (or coherence) of such technology choice in relation to the future vision that practitioners wish to achieve. Since some specific features of the desired future are clearly defined (e.g., better integrated electricity market), the context where technologies will act is already in part decided, and such argumentations act in order to filter in or out specific possibilities to be taken into account in the final solution.

This process is applied in different cases to mold the backbone of the targeted vision of the future. One example is the recent case of the so called "diesel gate", which is assumed to represent a discouraging event for the diesel vehicle market that will eventually lead to a stabilization of sales in the next future within the 4DS scenario ([16], p. 66). Another example is the pioneering experience of Norway in employing winning policies supporting EVs diffusion that is brought as an encouraging motivation to believe that the Nordics can reach world record figures in terms of BE electric vehicles deployment within 2050 based on the Norwegian experience, as outlined by the CNS results ([16], p. 64). On the other hand, the already wide spread of policies limiting car ownership and car operation among the Nordics, such as fuel and vehicle taxes or road pricing, are considered a possible reason for inefficacy of further future measures encouraging transport avoidance or modal shift from cars to, for example, public transport (due to limited potential). For this reason, vehicle ownership per capita is assumed to grow, with the same slow trend as today within both the 4DS and the CNS ([16], p. 68).

\section{References}

1. International Energy Agency. Energy Technology Perspectives 2016: Towards Sustainable Energy Systems; IEA Publications: Paris, France, 2016.

2. International Energy Agency. Energy Technology Perspectives 2015; IEA Publications: Paris, France, 2015.

3. International Transport Forum. Transport $\mathrm{CO}_{2}$ and Paris Agreement Reviewing the Impact of Nationally Determined Contributions; ITF Publications: Paris, France, 2018.

4. International Energy Agency. Energy Technology Perspectives 2014; IEA Publications: Paris, France, 2014.

5. International Energy Agency. Nordic EV Outlook 2018; IEA Publications: Paris, France, 2018.

6. Nordic Council of Ministers. Energy and Transport; TemaNord: Copenhagen, Denmark, 2014. [CrossRef]

7. Nordic Action Group on Climate and Energy. Nordic Transport Ways; Global Utmaning: Stockholm, Sweden, 2015.

8. Lopion, P.; Markewitz, P.; Robinius, M.; Stolten, D. A review of current challenges and trends in energy systems modeling. Renew. Sustain. Energy Rev. 2018, 96, 156-166. [CrossRef] 
9. Münster, M.; Morthorst, P.E.; Larsen, H.V.; Bregnbæk, L.; Werling, J.; Lindboe, H.H.; Ravn, H. The role of district heating in the future Danish energy system. Energy 2012, 48, 47-55. [CrossRef]

10. Petrović, S.N.; Karlsson, K.B. Residential heat pumps in the future Danish energy system. Energy 2016, 114, 787-797. [CrossRef]

11. Tattini, J.; Gargiulo, M.; Karlsson, K. Reaching carbon neutral transport sector in Denmark—Evidence from the incorporation of modal shift into the TIMES energy system modeling framework. Energy Policy 2018, 113, 571-583. [CrossRef]

12. Börjesson, M.; Ahlgren, E.O.; Lundmark, R.; Athanassiadis, D. Biofuel futures in road transport-A modeling analysis for Sweden. Transp. Res. Part D Transp. Environ. 2014, 32, 239-252. [CrossRef]

13. Tattini, J.; Mulholland, E.; Venturini, G.; Ahancian, M.; Gargiulo, M.; Balyk, O. A Long-Term Strategy to Decarbonise the Danish Inland Passenger Transport Sector. In Limiting Global Warming to Well Below $2{ }^{\circ} \mathrm{C}$ : Energy System Modelling and Policy Development; Giannakidis, G., Karlsson, K., Labriet, M., Ó Gallachóir, B., Eds.; Lecture Notes in Energy; Springer: Berlin, Germany, 2018; Volume 64, pp. 137-153. [CrossRef]

14. Shafiei, E.; Davidsdottir, B.; Leaver, J.; Stefansson, H.; Asgeirsson, E.I. Potential impact of transition to a low-carbon transport system in Iceland. Energy Policy 2014, 69, 127-142. [CrossRef]

15. Rosenberg, E.; Fidje, A.; Espegren, K.A.; Stiller, C.; Svensson, A.M.; Møller-Holst, S. Market penetration analysis of hydrogen vehicles in Norwegian passenger transport towards 2050. Int. J. Hydrogen Energy 2010, 35, 7267-7279. [CrossRef]

16. International Energy Agency, Nordic Energy Research. Nordic Energy Technology Perspectives 2016; IEA Publications: Paris, France; Oslo, Norway, 2016. [CrossRef]

17. Web of Science. Available online: https://www.webofknowledge.com (accessed on 13 March 2019).

18. DTU Findit. Available online: https:/findit.dtu.dk (accessed on 13 March 2019).

19. Scopus. Available online: https://www.scopus.com (accessed on 13 March 2019).

20. International Energy Agency. Nordic Energy Technology Perspectives 2016. Available online: https: //www.iea.org/etp/nordic/ (accessed on 12 July 2017).

21. Liu, Z.; Wu, Q.; Nielsen, A.; Wang, Y. Day-Ahead Energy Planning with $100 \%$ Electric Vehicle Penetration in the Nordic Region by 2050. Energies 2014, 7, 1733-1749. [CrossRef]

22. Graabak, I.; Wu, Q.; Warland, L.; Liu, Z. Optimal planning of the Nordic transmission system with $100 \%$ electric vehicle penetration of passenger cars by 2050. Energy 2016, 107, 648-660. [CrossRef]

23. Juul, N.; Meibom, P. Road transport and power system scenarios for Northern Europe in 2030. Appl. Energy 2012, 92, 573-582. [CrossRef]

24. Taljegard, M.; Göransson, L.; Odenberger, M.; Johnsson, F. Impacts of electric vehicles on the electricity generation portfolio-A Scandinavian-German case study. Appl. Energy 2019, 235, 1637-1650. [CrossRef]

25. Ravn, H. Balmorel Energy System Model. Available online: http://www.balmorel.com/ (accessed on 12 July 2017).

26. Bright, R.M.; Strømman, A.H. Fuel-Mix, Fuel Efficiency, and Transport Demand Affect Prospects for Biofuels in Northern Europe. Environ. Sci. Technol. 2010, 44, 2261-2269. [CrossRef] [PubMed]

27. Krook-Riekkola, A.; Sandberg, E. Net-Zero $\mathrm{CO}_{2}$-Emission Pathways for Sweden by Cost-Efficient Use of Forestry Residues. In Limiting Global Warming to Well Below $2{ }^{\circ} \mathrm{C}$ : Energy System Modelling and Policy Development; Giannakidis, G., Karlsson, K., Labriet, M., Ó Gallachóir, B., Eds.; Lecture Notes in Energy; Springer: Berlin, Germany, 2018; Volume 64, pp. 123-136.

28. Meibom, P.; Karlsson, K. Role of hydrogen in future North European power system in 2060. Int. J. Hydrogen Energy 2010, 35, 1853-1863. [CrossRef]

29. Sørensen, B. A renewable energy and hydrogen scenario for northern Europe. Int. J. Energy Res. 2008, 32, 471-500. [CrossRef]

30. Koljonen, T.; Pursiheimo, E.; Gether, K.; Jøregensen, K. System Analysis and Assessment of Technological Alternatives for Nordic H2 Energy Foresight; Risø National Laboratory: Roskilde, Denmark, 2004.

31. Klitkou, A.; Bolwig, S.; Coenen, L.; Solér, O.; Scordato, L. Technology Opportunities in Nordic Energy System Transitions (TOP-NEST); Nordic Institute for Studies in Innovation, Research and Education: Oslo, Norway, 2015.

32. Seljom, P.; Rosenberg, E. A Scandinavian Transition Towards a Carbon-Neutral Energy System. In Limiting Global Warming to Well Below $2^{\circ} \mathrm{C}$ : Energy System Modelling and Policy Development; Giannakidis, G., Karlsson, K., Labriet, M., Gallachóir, B., Eds.; Lecture Notes in Energy; Springer: Berlin, Germany, 2018; Volume 64, pp. 105-121. 
33. Pursiheimo, E.; Holttinen, H.; Koljonen, T. Path toward 100\% renewable energy future and feasibility of power-to-gas technology in Nordic countries. IET Renew. Power Gener. 2017, 11, 1695-1706. [CrossRef]

34. Loulou, R.; Goldstein, G.; Kanudia, A.; Lehtilä, A.; Remme, U. Documentation for the TIMES Model—Part I: TIMES Concepts and Theory. Available online: https://iea-etsap.org/index.php/documentation (accessed on 12 July 2017).

35. Sovacool, B.K. Contestation, contingency, and justice in the Nordic low-carbon energy transition. Energy Policy 2017, 102, 569-582. [CrossRef]

36. Haasz, T.; Vilchez, J.J.; Kunze, R.; Deane, P.; Fraboulet, D.; Fahl, U.; Mulholland, E. Perspectives on decarbonizing the transport sector in the EU-28. Energy Strateg. Rev. 2018, 20, 124-132. [CrossRef]

37. World Energy Council, IBM Corporation, Paul Scherrer Institute. Global Transport Scenarios 2050; World Energy Council: London, UK, 2011.

38. Fulton, L.; Cazzola, P.; Cuenot, F. IEA Mobility Model (MoMo) and its use in the ETP 2008. Energy Policy 2009, 37, 3758-3768. [CrossRef]

39. International Energy Agency. Modelling of the Transport Sector in the Mobility Model 2017. Available online: https://www.iea.org/etp/etpmodel/transport/ (accessed on 12 July 2017).

40. Cuenot, F.; Fulton, L.; Staub, J. The prospect for modal shifts in passenger transport worldwide and impacts on energy use and $\mathrm{CO}_{2}$. Energy Policy 2012, 41, 98-106. [CrossRef]

41. Yeh, S.; Mishra, G.S.; Fulton, L.; Kyle, P.; McCollum, D.L.; Miller, J.; Cazzola, P.; Teter, J. Detailed assessment of global transport-energy models' structures and projections. Transp. Res. Part D Transp. Environ. 2016, 1-16. [CrossRef]

42. Schipper, L.; Marie-Lilliu, C.; Gorham, R. Flexing the Link between Transport and Greenhouse Gas Emissions; IEA Publications: Paris, France, 2000.

43. Cazzola, P.; (International Energy Agency, Paris, France). Personal communication, 2017.

44. Wråke, M.; (Swedish Energy Research Centre-Energiforsk, Stockholm, Sweden). Personal communication, 2017.

45. Daly, H.E.; Ramea, K.; Chiodi, A.; Yeh, S.; Gargiulo, M.; Gallachóir, B.Ó. Incorporating travel behaviour and travel time into TIMES energy system models. Appl. Energy 2014, 135, 429-439. [CrossRef]

46. Pye, S.; Daly, H. Modelling sustainable urban travel in a whole systems energy model. Appl. Energy 2015, 159, 97-107. [CrossRef]

47. Tattini, J.; Ramea, K.; Gargiulo, M.; Yang, C.; Mulholland, E.; Yeh, S.; Karlsson, K. Improving the representation of modal choice into bottom-up optimization energy system models-The MoCho-TIMES model. Appl. Energy 2018, 212, 265-282. [CrossRef]

48. Cayla, J.-M.; Maïzi, N. Integrating household behavior and heterogeneity into the TIMES-Households model. Appl. Energy 2015, 139, 56-67. [CrossRef]

49. Salvucci, R.; Tattini, J.; Gargiulo, M.; Lehtilä, A.; Karlsson, K. Modelling transport modal shift in TIMES models through elasticities of substitution. Appl. Energy 2018, 232, 740-751. [CrossRef]

50. Connolly, D. Economic viability of electric roads compared to oil and batteries for all forms of road transport. Energy Strateg. Rev. 2017, 18, 235-249. [CrossRef]

51. Ahjum, F.; Merven, B.; Stone, A.; Caetano, T. Road transport vehicles in South Africa towards 2050: Factors influencing technology choice and implications for fuel supply. J. Energy S. Afr. 2018, 29, 33-55. [CrossRef]

52. Ishimoto, Y.; Kurosawa, A.; Sasakura, M.; Sakata, K. Significance of $\mathrm{CO}_{2}$-free hydrogen globally and for Japan using a long-term global energy system analysis. Int. J. Hydrogen Energy 2017, 42, 13357-13367. [CrossRef]

53. Oshiro, K.; Masui, T. Diffusion of low emission vehicles and their impact on $\mathrm{CO} 2$ emission reduction in Japan. Energy Policy 2015, 81, 215-225. [CrossRef]

54. Kawakami, Y.; Komiyama, R.; Fujii, Y. Penetration of Electric Vehicles toward 2050: Analysis Utilizing an Energy System Model Incorporating High-Temporal-Resolution Power Generation Sector. IFAC-PapersOnLine 2018, 51, 598-603. [CrossRef]

55. Teir, S.; Tsupari, E.; Arasto, A.; Koljonen, T.; Kärki, J.; Lehtilä, A.; Kujanpää, L.; Aatos, S.; Nieminen, M. Prospects for application of CCS in Finland. Energy Procedia 2011, 4, 6174-6181. [CrossRef]

56. Victor, N.; Nichols, C.; Zelek, C. The U.S. power sector decarbonization: Investigating technology options with MARKAL nine-region model. Energy Econ. 2018, 73, 410-425. [CrossRef]

57. Huang, W.; Chen, W.; Anandarajah, G. The role of technology diffusion in a decarbonizing world to limit global warming to well below $2{ }^{\circ} \mathrm{C}$ : An assessment with application of Global TIMES model. Appl. Energy 2017, 208, 291-301. [CrossRef] 
58. Simoes, S.; Nijs, W.; Ruiz, P.; Sgobbi, A.; Thiel, C. Comparing policy routes for low-carbon power technology deployment in EU-An energy system analysis. Energy Policy 2017, 101, 353-365. [CrossRef]

59. Blanco, H.; Nijs, W.; Ruf, J.; Faaij, A. Potential for hydrogen and Power-to-Liquid in a low-carbon EU energy system using cost optimization. Appl. Energy 2018, 232, 617-639. [CrossRef]

60. Schäfer, A. Introducing Behavioral Change in Transportation into Energy/Economy/Environment Models; World Bank policy research working paper no. WPS 6234; World Bank: Washington, DC, USA, 2012.

61. Venturini, G.; Tattini, J.; Mulholland, E.; Ó Gallachóir, B. Improvements in the representation of behaviour in integrated energy and transport models. Int. J. Sustain. Transp. 2018, 13, 294-313. [CrossRef]

62. Baptista, P.; Melo, S.; Rolim, C. Energy, Environmental and Mobility Impacts of Car-sharing Systems. Empirical Results from Lisbon, Portugal. Procedia Soc Behav. Sci. 2014, 111, 28-37. [CrossRef]

63. International Energy Agency. Transport Energy and $\mathrm{CO}_{2}$; IEA Publications: Paris, France, 2009.

64. European Commission. White Paper. Roadmap to a Single European Transport Area-Towards a Competitive and Resource Efficient Transport System; European Commission: Brussels, Belgium, 2011.

65. Iacobucci, R.; McLellan, B.; Tezuka, T. The Synergies of Shared Autonomous Electric Vehicles with Renewable Energy in a Virtual Power Plant and Microgrid. Energies 2018, 11, 2016. [CrossRef]

66. International Energy Agency. The Future of Trucks-Implications for Energy and the Environment; IEA Publications: Paris, France, 2017.

67. Martinsen, K.; Torvanger, A. Control Mechanisms for Nordic Ship Emissions; TemaNord, Nordic Council of Ministers: Copenhagen, Denmark, 2013.

68. Gagatsi, E.; Estrup, T.; Halatsis, A. Exploring the Potentials of Electrical Waterborne Transport in Europe: The E-ferry Concept. Transp. Res. Procedia 2016, 14, 1571-1580. [CrossRef]

69. Rootzén, J.; Johnsson, F. $\mathrm{CO}_{2}$ emissions abatement in the Nordic carbon-intensive industry-An end-game in sight? Energy 2015, 80, 715-730. [CrossRef]

70. Rydén, M.; Lyngfelt, A.; Langørgen, Ø.; Larring, Y.; Brink, A.; Teir, S.; Havåg, H.; Karmhagen, P. Negative $\mathrm{CO}_{2}$ Emissions with Chemical-Looping Combustion of Biomass-A Nordic Energy Research Flagship Project. Energy Procedia 2017, 114, 6074-6082. [CrossRef]

71. Anthonsen, K.L.; Aagaard, P.; Bergmo, P.E.; Erlström, M.; Fareide, J.I.; Gislason, S.R.; Mortensen, G.M.; Snæbjörnsdottir, S.Ó. $\mathrm{CO}_{2}$ Storage Potential in the Nordic Region. Energy Procedia 2013, 37, 5080-5092. [CrossRef]

72. Mustapha, W.F.; Bolkesjø, T.F.; Martinsen, T.; Trømborg, E. Techno-economic comparison of promising biofuel conversion pathways in a Nordic context_Effects of feedstock costs and technology learning. Energy Convers. Manag. 2017, 149, 368-380. [CrossRef]

73. Börjesson, M.; Grahn, M.; Ahlgren, E. Transport Biofuel Futures in Energy-Economic Modeling-A Review; The Swedish Knowledge Centre for Renewable Transportation Fuels: Göteborg, Sweden, 2013.

74. Brynolf, S.; Taljegard, M.; Grahn, M.; Hansson, J. Electrofuels for the transport sector: A review of production costs. Renew. Sustain. Energy Rev. 2018, 81, 1887-1905. [CrossRef]

75. Goldmann, A.; Sauter, W.; Oettinger, M.; Kluge, T.; Schröder, U.; Seume, J.; Friedrichs, J.; Dinkelacker, F. A Study on Electrofuels in Aviation. Energies 2018, 11, 392. [CrossRef]

76. Mustapha, W.F.; Kirkerud, J.G.; Bolkesjø, T.F.; Trømborg, E. Large-scale forest-based biofuels production: Impacts on the Nordic energy sector. Energy Convers. Manag. 2019, 187, 93-102. [CrossRef]

77. Sgobbi, A.; Nijs, W.; De Miglio, R.; Chiodi, A.; Gargiulo, M.; Thiel, C. How far away is hydrogen? Its role in the medium and long-term decarbonisation of the European energy system. Int. J. Hydrogen Energy 2016, 41, 19-35. [CrossRef]

78. Næss, P.; Jensen, O.B. Urban structure matters, even in a small town. J. Environ. Plan Manag. 2004, 47, 35-57. [CrossRef]

79. Krumdieck, S.; Page, S.; Dantas, A. Urban form and long-term fuel supply decline: A method to investigate the peak oil risks to essential activities. Transp. Res. Part A Policy Pract. 2010, 44, 306-322. [CrossRef]

80. Forsberg, J.; Krook-Riekkola, A. Supporting Cities' Emission Mitigation StrategieS: Modelling Urban Transport in a Times Energy System Modelling Framework. In Proceedings of the 17th International Conference on Urban Transport and the Environment, University of Rome 'La Sapienza', Rome, Italy, 5-7 September 2017; Ricci, S., Brebbia, C.A., Eds.; Wessex Institute: Ashurst, UK, 2017; pp. 15-25. [CrossRef]

81. Lind, A.; Espegren, K. The use of energy system models for analysing the transition to low-carbon cities-The case of Oslo. Energy Strateg. Rev. 2017, 15, 44-56. [CrossRef] 
82. Sovacool, B.K.; Noel, L.; Kester, J.; Zarazua de Rubens, G. Reviewing Nordic transport challenges and climate policy priorities: Expert perceptions of decarbonisation in Denmark, Finland, Iceland, Norway, Sweden. Energy 2018, 165, 532-542. [CrossRef]

83. Joint Research Centre. Well-To-Wheels Report Version 4.a-Well-To-Wheels Analysis of Future Automotive Fuels and Powertrains in the European Context; Publications Office of the European Union: Luxembourg, 2014. [CrossRef]

84. Joint Research Centre. Well-To-Tank Report Version 4.0-Well-To-Wheels Analysis of Future Automotive Fuels and Powertrains in the European Context; Publications Office of the European Union: Luxembourg, 2013. [CrossRef]

85. Stocker, T.F.; Qin, D.; Plattner, G.-K.; Tignor, M.; Allen, A.K.; Boschung, J.; Nauels, A.; Xia, Y.; Bex, V.; Midgley, P.M. Climate Change 2013: The Physical Science Basis. Contribution of Working Group I to the Fifth Assessment Report of the Intergovernmental Panel on Climate Change; Cambridge University Press: Cambridge, UK; New York, NY, USA, 2013.

86. United Nations, Department of Economic and Social Affairs. World Urbanization Prospects: The 2014 Revision, CD-ROM Edition 2014; United Nations Publications: New York, NY, USA, 2015.

87. Koljonen, T.; (Technical Research Centre of Finland-VTT, Espoo, Finland). Personal communication, 2017.

88. Espegren, K.A.; (Institute for Energy Technology, Kjeller, Norway). Personal communication, 2017.

89. Börjeson, L.; Höjer, M.; Dreborg, K.H.; Ekvall, T.; Finnveden, G. Scenario types and techniques: Towards a user's guide. Futures 2006, 38, 723-739. [CrossRef]

(C) 2019 by the authors. Licensee MDPI, Basel, Switzerland. This article is an open access article distributed under the terms and conditions of the Creative Commons Attribution (CC BY) license (http://creativecommons.org/licenses/by/4.0/). 